\title{
EMPREENDEDORISMO IMIGRANTE E ÉTNICO: O PAPEL DAS REDES SOCIAIS NO PROCESSO EMPREENDEDOR DE IMIGRANTES SÍRIOS NO BRASIL
}

Gislene Cordeiro Da Silva Diniz ${ }^{1}$

Liliane De Oliveira Guimarães ${ }^{1}$

Duval Magalhães Fernandes ${ }^{1}$

${ }^{1}$ Pontifícia Universidade Católica de Minas Gerais - PUC Minas 


\section{EMPREENDEDORISMO IMIGRANTE E ÉTNICO: O PAPEL DAS REDES SOCIAIS NO PROCESSO EMPREENDEDOR DE IMIGRANTES SÍRIOS NO BRASIL}

Resumo: este estudo procurou compreender e analisar o papel das redes sociais no empreendedorismo de imigrantes sírios no Brasil. Com o uso da metodologia história de vida, buscou-se identificar e descrever os tipos de recursos que são oferecidos pelas redes sociais, analisando o papel dessas redes no empreendedorismo de imigrantes. Os resultados confirmaram estudos relatados na literatura, ou seja, as redes sociais representam fontes de vários tipos de recursos, entre eles capital financeiro, social e humano e ainda atuam como apoio emocional e de aconselhamento que, aliados, favorecem o empreendedorismo imigrante e étnico. A pesquisa também confirmou que as redes sociais são ferramentas valiosas para a criação e manutenção de novos negócios.

\section{Palavras-chave: Empreendedorismo Imigrante. Empreendedorismo Étnico. Redes Sociais. Imigrantes Sírios.}

\section{Introdução}

Atualmente as imigrações internacionais têm crescido de forma expressiva em nível mundial, causando impactos de diferentes ordens em vários países no mundo, gerando tensões políticas e econômicas. Esse fenômeno migratório sempre foi um ato presente na sociedade e resulta consequências econômicas e sociais para os países envolvidos (Martes, 2016). Atualmente, tem havido grande preocupação dos governos em discutir e pensar estratégias para acolher o grande contingente de imigrantes que, carregados de sonhos e esperança, deixam para trás suas histórias, famílias, bens, entre outros, para reiniciar a vida em outro país. Se o grande fluxo de imigrantes pode causar transtornos para o país de destino, por outro lado, a literatura sobre o tema mostra que a migração internacional pode proporcionar crescimento econômico e desenvolvimento regional com a participação dos imigrantes não apenas no mercado de trabalho, mas também como empreendedores (Lima \& Castro, 2017).

De acordo com dados da pesquisa internacional realizada no período de 2010 a 2015 pelo Global Migration Data Analysis Centre (GMDAC) e pela International Organization for Migration (IOM), divulgados em 2017, cerca de 710 milhões de pessoas em todo o mundo expressam o desejo de migrar para algum país no exterior. $\mathrm{O}$ destino mais desejado são os Estados Unidos, e o Brasil aparece na lista dos 20 mais procurados pelos imigrantes (GMDAC, 2017). Pesquisas empíricas realizadas por Halter (2007), Light (1972, 1979), Lima e Castro (2017), Portes \& Zou (1992), Sanders \& Nee (1996), Wilson \& Portes (1980) e Zhou (2004) demonstram que, ao se estabelecer em um novo país, o imigrante encontra um novo contexto social e econômico e fatores que o condicionam a buscar recursos que o ajudem a sobreviver no país de acolhimento. Dadas as inúmeras dificuldades de adaptação em país estrangeiro, muitos imigrantes encontram na informalidade seu sustento e buscam no empreendedorismo uma forma de gerar renda e se inserir econômica e socialmente. Com a indisponibilidade de recursos financeiros oriundos de instituições formais de crédito dado ao seu status, muitas vezes, de irregular ou ilegal, parecem contar com o apoio de suas redes sociais para iniciar um negócio e promover o desenvolvimento de seu empreendimento.
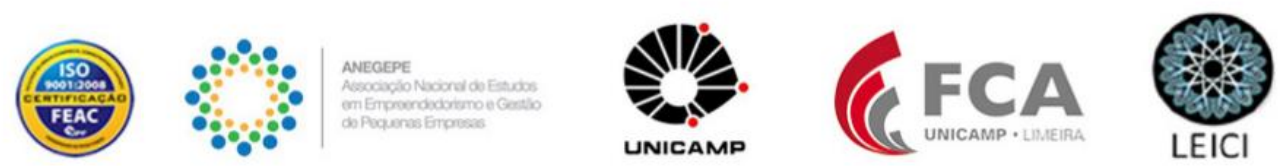
Considerando o exposto, estabeleceu-se como questão norteadora para este trabalho: como as redes sociais no país de acolhimento atuam no apoio aos negócios dos empreendedores imigrantes sírios no Brasil? O artigo foi estruturado da seguinte forma: após esta introdução, estabelece-se o referencial teórico que norteou a pesquisa e a análise dos dados coletados. No item 3 descreve-se a metodologia utilizada no trabalho de investigação. No item 4 apresenta-se o caso do imigrante empreendedor sírio e, no item 5, a análise da sua trajetória empreendedora e do papel da rede no processo. Por fim, no item 6, as considerações finais do trabalho.

\section{Referencial Teórico}

\subsection{Empreendedorismo imigrante}

O empreendedor imigrante tem conquistado a atenção de diversos estudiosos sobre o tema, tais como Light (1972), Portes (1981, 2003), Portes e Zhou (1992, 2012), Portes e Jensen (1989), Portes \& Rumbaut (2006), Portes \& Sensenbrenner (1993), Zhou (2004), Portes \& Shafer (2007), Aldrich \& Ward (1990), Sanders \& Nee (1996, 1987), Martes e Rodrigues (2004) e Halter (2007), entre outros. Os estudos realizados documentam conceitos importantes para a diferenciação do tipo de negócio exercido pelo imigrante e em que âmbito ele ocorre. Dessa maneira, para se discutir o empreendedorismo imigrante é importante reconhecer suas diferentes denominações e suas peculiaridades. De acordo com Halter (2007), ao chegar ao país de acolhimento, alguns imigrantes enfrentam uma série de barreiras, tais como falta de proficiência na nova língua, baixo nível de escolaridade, falta de documentos com permissão para trabalhar no país, choques culturais e falta de aceitação e reconhecimento como pessoa pertencente àquela sociedade. Por vezes, esse cenário torna sua adaptação complexa e esse volume de barreiras torna os imigrantes menos competitivos no mercado de trabalho formal, o que estimula iniciativas empreendedoras entre os imigrantes, como forma de superar as restrições econômicas e de sobrevivência dessa população (Halter, 2007; Oliveira, 2007; Portes \& Jensen, 1989; Zhou, 2004). Nesse sentido, Peroni, Riilio \& Sarracino (2016) tentam explicar a relação entre imigração e o empreendedorismo. Conforme os autores, os imigrantes em situações de desvantagens linguísticas, raciais e educacionais são mais propensos a empreender. Outros estudos destacam o papel dos traços culturais herdados de seus países de origem como facilitadores da manifestação de iniciativas empreendedoras. A partir da teoria do capital humano, Sanders \& Nee (1996) e Arregle, Batjargal, Hitt, Webb, Miller \& Tsui (2015) apregoam que as redes sociais dos imigrantes exercem papel de facilitador de acessos a recursos de mão de obra, financeiros e de suporte emocional-familiar.

Zhou (2004), analisando o empreendedorismo de imigrantes ressalta, como determinante as condições ou contexto de saída do imigrante de seu país de origem. Na sua avaliação, em alguns casos, o imigrante leva consigo recursos como capital humano, motivação e até mesmo recursos financeiros, possuindo, assim, vantagem em relação aos demais imigrantes, que muitas vezes enfrentam as barreiras já mencionadas. Estudos seminais como o de Portes \& Jensen (1989), Zhou (2004), Sanders \& Nee (1987) analisam a questão do enclave étnico, definindo-o como o local onde membros de grupos e comunidades étnicas residem. A ideia central da perspectiva é que o imigrante aumenta sua chance de iniciar um novo negócio em áreas de enclave étnico, uma vez que é alto o nível de solidariedade e valores culturais partilhados entre o grupo ou comunidade. A teoria do embeddedness ou enraizamento/imersão sugere que os imigrantes pertencentes a redes étnicas alavancam suas possibilidades de

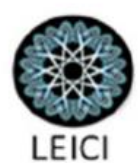


empreender, haja vista que os membros integrantes dessa rede podem fornecer aos imigrantes coétnicos diversos tipos de recursos como, por exemplo, capital financeiro e capital social (Granovetter, 1985; Peroni et al., 2016).

Além das perspectivas que tentam explicar os motivos que levam o imigrante a empreender, é necessário definir quem são os atores envolvidos nesse processo. Zhou (2004), Halter (2007) e Cruz, Falcão e Barreto (2017) conceituam empreendedores étnicos como aqueles que possuem negócio próprio, que estejam ligados de forma comum a uma herança cultural, compartilhando da mesma estrutura social, comportamental e nas transações econômicas comuns ao grupo. Esclarecem sobre a diferença entre empreendedor imigrante e empreendedor étnico, sendo que a principal característica do empreendedor imigrante é que ele não se identifica com sua comunidade étnica, seja por diferenças nas práticas comerciais, nas comportamentais, por valores culturais divergentes ou até mesmo por não considerar seus compatriotas. Normalmente faz a opção por tipos de negócios não relacionados à sua etnia e busca se dissociar e diferenciar de seu grupo étnico. No trabalho de Zhou (2004), são estabelecidas duas categorias de empreendedorismo étnico, como, por exemplo: minoria intermediária e empresários de enclave. A categoria denominada minoria intermediária é composta por grupos étnicos que realizam atividades econômicas e são mediadores nas negociações entre a elite e as massas do enclave. Normalmente estabelecem nichos de mercado étnicos em bairros onde a maioria da população é de baixa renda ou em guetos de imigrantes, a fim de atenderem às demandas dos coétnicos que comumente não são oferecidas pela economia tradicional. De acordo com Zhou (2004), os empresários de enclaves se diferenciam principalmente por seus negócios se autossustentarem pela população pertencente ao enclave étnico e normalmente desempenham duplo papel como minoria intermediária e empresário de enclave. Como exemplo de empresário de minoria intermediário Zhou (2004) relata um imigrante chinês que gerencia um restaurante de fast food em um bairro onde a maioria da população é latina. Entretanto, tornar-se-ia um empresário de enclave quando retornasse para o restaurante de sua propriedade em Chinatown, bairro de enclave chinês na cidade de New York. Essas categorias de empreendedorismo apresentam novos conceitos, como o de economia étnica e o de economia de enclave. Ambos estão relacionados entre si. O conceito de economia étnica abrange empresas de minorias intermediárias, empresas de coétnicos localizadas em enclaves étnicos e empresas étnicas atuantes na economia em geral. A mobilidade entre as pessoas pertencentes a esses grupos cria oportunidades de empreendedorismo e empregos para seus coétnicos (Zhou, 2004).

O conceito de economia de enclave foi apresentado por Wilson \& Portes (1980), baseado no mercado de trabalho de cubanos na cidade de Miami. Inclui quase todos os tipos de negócios, funcionando como um guarda-chuva étnico. Suas atividades econômicas incluem o comércio e a produção voltada para o mercado em geral e não apenas nichos evitados por nativos. A economia de enclave também é alimentada por solidariedade limitada e confiança. É limitada, pois se restringe apenas aos membros pertencentes ao grupo e inicialmente não tem relação apenas com questões de cunho financeiro. O que a estabelece é a situação comum de adversidade vivenciada. A comunidade étnica solidária também constitui fonte relevante para a economia étnica e de enclave, pois são celeiros de mão de obra barata e confiável, cujas disponibilidades desses recursos se tornam um diferencial para os empresários imigrantes (Portes \& Sensenbrenner, 1993). Enfim, na literatura que discute empreendedorismo imigrante

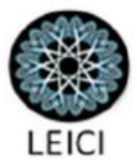


percebe-se a relevância do papel das redes sociais não apenas para facilitar e agilizar a adaptação do imigrante ao novo país, mas também como base de apoio para o estabelecimento de atividades empreendedoras. Elas são fontes de vários tipos de recursos, entre eles os capitais financeiro, social e humano, em que a solidariedade limitada e a confiança se tornam moedas de grande valia para o fortalecimento do espírito empreendedor imigrante (Zhou, 2004).

A Tabela 1 sintetiza as principais terminologias e definições para o empreendedorismo de imigrantes.

Tabela 1 - Principais terminologias encontradas no empreendedorismo de imigrantes

\begin{tabular}{|c|c|c|}
\hline Termo & Características & $\begin{array}{l}\text { Principais } \\
\text { Autores } \\
\end{array}$ \\
\hline $\begin{array}{l}\text { Empreendedorismo } \\
\text { imigrante }\end{array}$ & $\begin{array}{l}\text { Normalmente faz a opção por tipos de } \\
\text { negócios não relacionados à sua etnia e busca se } \\
\text { dissociar e diferenciar de seu grupo étnico. }\end{array}$ & $\begin{array}{l}\text { Zhou, 2004; Cruz } \\
\text { et al., } 2017\end{array}$ \\
\hline $\begin{array}{c}\text { Empreendedorismo } \\
\text { étnico }\end{array}$ & $\begin{array}{l}\text { Identifica-se e mantém relacionamento } \\
\text { com coétnicos, define estratégias de negócios } \\
\text { voltadas para público da mesma etnia voltado para } \\
\text { o enclave. }\end{array}$ & $\begin{array}{l}\text { Zhou, 2004; Cruz } \\
\text { et al., } 2017\end{array}$ \\
\hline Enclave étnico & $\begin{array}{l}\text { Pode ser definido como o local onde } \\
\text { membros de grupos e comunidades étnicas } \\
\text { residem. }\end{array}$ & $\begin{array}{r}\text { Portes \& Jensen, } \\
\text { 1989; Zhou, 2004; Light \& } \\
\text { Karageorgis, 1994; Sanders } \\
\text { \& Nee, } 1987 \\
\end{array}$ \\
\hline $\begin{array}{l}\text { Minoria étnica } \\
\text { intermediária }\end{array}$ & $\begin{array}{l}\text { Composta por grupos étnicos que realizam } \\
\text { atividades econômicas e são intermediários nas } \\
\text { negociações entre a elite e as massas do enclave. } \\
\text { Atendem às demandas dos coétnicos que não são } \\
\text { oferecidas pela economia tradicional. }\end{array}$ & $\begin{array}{c}\text { Zhou, 2004; } \\
\text { Wilson \& Portes, } 1980\end{array}$ \\
\hline $\begin{array}{l}\text { Economia de } \\
\text { enclave }\end{array}$ & $\begin{array}{l}\text { Inclui quase todos os tipos de negócios, } \\
\text { funciona como um guarda-chuva, suas atividades } \\
\text { econômicas incluem o comércio e a produção } \\
\text { direcionada ao mercado em geral, diversidade nos } \\
\text { negócios e ampla variedade de atividades } \\
\text { econômicas e não apenas nichos evitados por } \\
\text { nativos. }\end{array}$ & $\begin{array}{l}\text { Wilson \& Portes, } \\
\text { 1980; } \\
\text { Zhou, } 2004\end{array}$ \\
\hline Economia étnica & $\begin{array}{l}\text { O conceito de economia étnica abrange } \\
\text { empresas de minorias intermediárias, empresas de } \\
\text { coétnicos localizadas em enclaves étnicos e } \\
\text { empresas étnicas atuantes na economia em geral. }\end{array}$ & Zhou, 2004 \\
\hline $\begin{array}{l}\text { Solidariedade } \\
\text { limitada }\end{array}$ & $\begin{array}{l}\text { A solidariedade limitada inicialmente não } \\
\text { tem relação com questões de cunho financeiro. } \\
\text { Trata-se de solidariedade emergida das } \\
\text { adversidades comuns enfrentadas pelos imigrantes. } \\
\text { Pode criar normas de apoio mútuo, princípios e } \\
\text { comportamentos entre aquela comunidade. }\end{array}$ & $\begin{array}{c}\text { Portes \& } \\
\text { Sensenbrenner 1993; Zhou, } \\
2004\end{array}$ \\
\hline
\end{tabular}

Fonte: elaborado pelos autores. 


\subsection{Redes sociais e empreendedorismo imigrante}

As pesquisas empíricas realizadas por diversos pesquisadores tais como Granovetter (1973, 1985, 1992, 2005), Martes e Rodrigues (2004), Zhou (2004), Sanders \& Nee (1996), Portes \& Jensen (1989), Light \& Karageorgis (1994), Arregle et al. (2015), Wilson \& Portes (1980), Mariz e Bógus (2013), Peroni et al. (2016), Corrêa e Vale (2017), Vale e Guimarães (2010), Vasconcelos, Rezende, Guimarães \& Fachin (2007), entre outros, têm demonstrado que as redes sociais são ferramentas importantes e essenciais para o desenvolvimento do empreendedorismo, inclusive como fonte de recursos financeiros, sociais e até mesmo emocionais. Os laços existentes entre indivíduos constituem papel fundamental para o entendimento de como os mesmos influenciam o empreendedorismo. Granovetter (1973) propõe duas definições quanto aos tipos de laços, denominando-os como laços fortes e laços fracos. São considerados laços fortes as relações mantidas entre indivíduos em que é possível verificar identidade comum. Assim, os laços fortes são encontrados entre pessoas próximas, do mesmo círculo social, entre parentes, familiares e amigos, ou seja, quanto maior a interação e similaridade entre os atores, maior a força do laço. E considera laços fracos aqueles mantidos entre indivíduos que são colegas ou conhecidos.

Corrêa \& Vale (2017) explicitam que por mais que os laços fortes proporcionem mais acessibilidade a recursos, eles não são capazes de fornecer a sustentação necessária ao empreendedorismo dos indivíduos interligados à rede. Nesse âmbito, Granovetter (1973) percebe a força dos laços fracos, pois esses tipos de laço geram redes que proporcionam grandes vantagens para seus membros, pois os mesmos exercem papel de pontes, transpondo distâncias e ampliando o universo de possibilidade. $\mathrm{O}$ autor ainda discute a densidade das redes e realça que para se verificar a densidade da rede é necessário averiguar a quantidade de laços existentes em cada uma. As redes que interagem com mais intensidade e mais frequência são consideradas eficazes e densas, formando grupos mais coesos. E são mais percebidas em grupos que convivem em cenário similar, como etnias, grupos com viés ideológico forte ou com aspectos profissionais comuns. As redes que interagem em menor grau (laços fracos) são denominadas rede estendida e são menos densas (Granovetter, 1973), podendo gerar mais benefícios, haja vista que a probabilidade de acesso a oportunidades e informações não redundantes é maior se comparada a redes densas (laços fortes). Corrêa e Vale (2017) complementam que a dinâmica entre laços fortes e laços fracos são fundamentais para a atividade empreendedora.

Ao discutir a relação imbricada entre atividade econômica e redes sociais embeddedness -, Granovetter (1985, 2005) mostra que as relações econômicas estão imersas nas relações sociais, e vice-versa. Acrescenta que a partir dessas interações é muito comum nascerem laços de amizade e confiança entre os atores, produzindo ganhos inicialmente não previstos. Para o empreendedorismo, esse conceito de embedded (imersão) é importante, pois empreendedores podem estar imersos em diversos tipos de redes formados pelas relações sociais e econômicas (Hite, 2003, 2005). Para a autora, os indivíduos podem estabelecer laços inicialmente apenas com a intenção de se relacionar no âmbito pessoal, porém esses relacionamentos podem evoluir para relações de caráter econômico, da mesma forma que os laços gerados por relações econômicas podem alargar o nível de confiança, gerando laços de amizades longevos (Granovetter, 1985).

Um conceito mais abrangente - capital social - é sugerido por Coleman (1988). O autor define o capital social como recursos oriundos das estruturas sociais dos atores, que podem ser

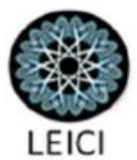


utilizados para a realização de interesses e objetivos próprios. E destaca três formas de capital: físico, humano e social. O capital físico é compreendido como elementos ligados à produção tais como ferramentas, máquinas e outros equipamentos. $\mathrm{O}$ capital humano diz respeito às habilidades e competências dos indivíduos. E capital social é aquele gerado a partir das mudanças e conexões das estruturas sociais de cada indivíduo. Portes \& Sensenbrenner (1993), Portes \& Zhou (1992), Granovetter (1973, 1983, 1985, 1992, 2005) e Zhou (2004) fazem menção ao capital social decorrente de reciprocidade e da solidariedade limitada. Esse tipo de capital surge entre indivíduos independentemente de valores financeiros. Eles estão pautados na solidariedade e nas normas criadas entre o grupo. A confiança é a base do relacionamento e pode gerar benefícios e proporcionar crescimento empresarial. Outra fonte de recursos importante para o empreendedorismo são os oriundos dos laços familiares. Eles podem oferecer diversos tipos de recursos em apoio ao empreendedor na superação dos desafios inerentes ao crescimento empresarial (Arregle et al., 2015; Portes \& Zhou, 1992; Sanders \& Nee, 1996).

Arregle et al. (2015) ressaltam que os laços de rede de empreendedores podem ser úteis de três maneiras: como rede de conselho, rede de recursos e rede de apoio emocional, sendo que cada tipo afeta de forma diferente o desenvolvimento dos negócios. As redes de conselho são valiosas para auxiliar o empreendedor a solucionar problemas que lhe causam incerteza, ajudando no reconhecimento de oportunidades de novos produtos ou serviços, em desenvolvimento de tecnologias e até mesmo em informações sobre alterações de leis e regulamentos. Elas facilitam o acesso ao conhecimento de mercado e às decisões de cunho financeiro (Arregle et al., 2015). Já as redes de apoio emocional proporcionam amparo psíquico e emocional, ajudando o empreendedor na superação dos dilemas inerentes à atividade empreendedora e facilitando sua concentração na consolidação e crescimento dos negócios (Arregle et al., 2015). E as denominadas redes de recursos são fontes de apoio a diversos tipos de recursos como capital financeiro, mão de obra, matéria-prima, tecnologias, entre outros. Essa diversidade de recursos disponibilizada pelas relações interpessoais e organizacionais permite o desenvolvimento de competências empreendedoras e o crescimento empresarial (Arregle et $a l .$, 2015). Enfim, a literatura acadêmica tem demonstrado, por meio das pesquisas empíricas, que as redes sociais são importantes no apoio ao empreendedorismo, e estas, por sua vez, podem proporcionar crescimento e gerar vantagens competitivas aos negócios.

A Tabela 2 apresenta os recursos disponibilizados pelas redes sociais aos empreendedores. 
Tabela 2- Recursos disponibilizados pelas redes sociais

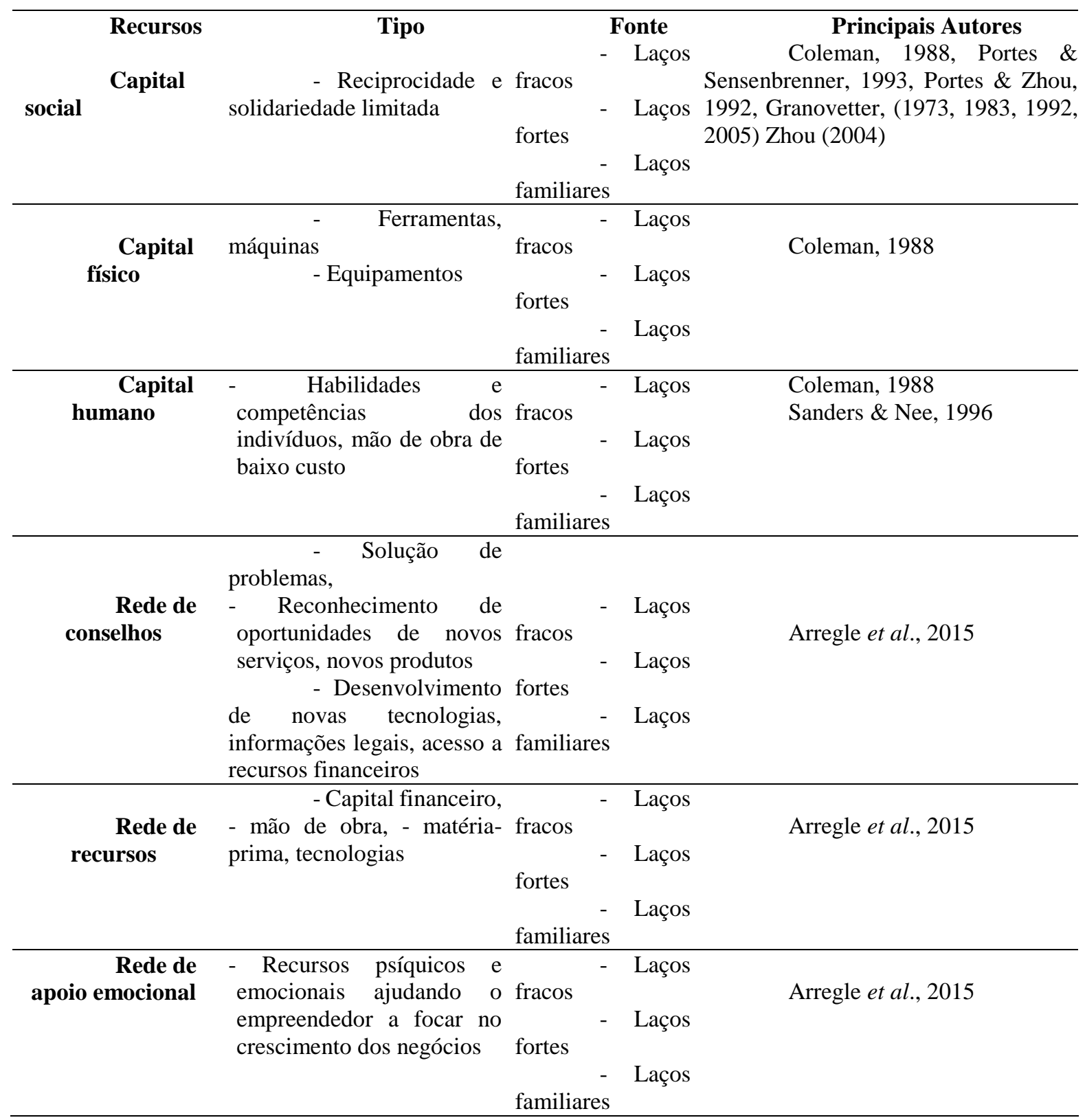

Fonte: elaborado pelos autores.

\subsection{Modelo teórico para análise dos dados}

A discussão sobre o empreendedorismo imigrante, bem como sobre o papel das redes sociais de apoio ao processo empreendedor, permitiu elaborar um modelo teórico para subsidiar a análise dos dados, conforme se segue. 
Figura 1 - Processo empreendedor imigrante

Processo Empreendedor Imigrante

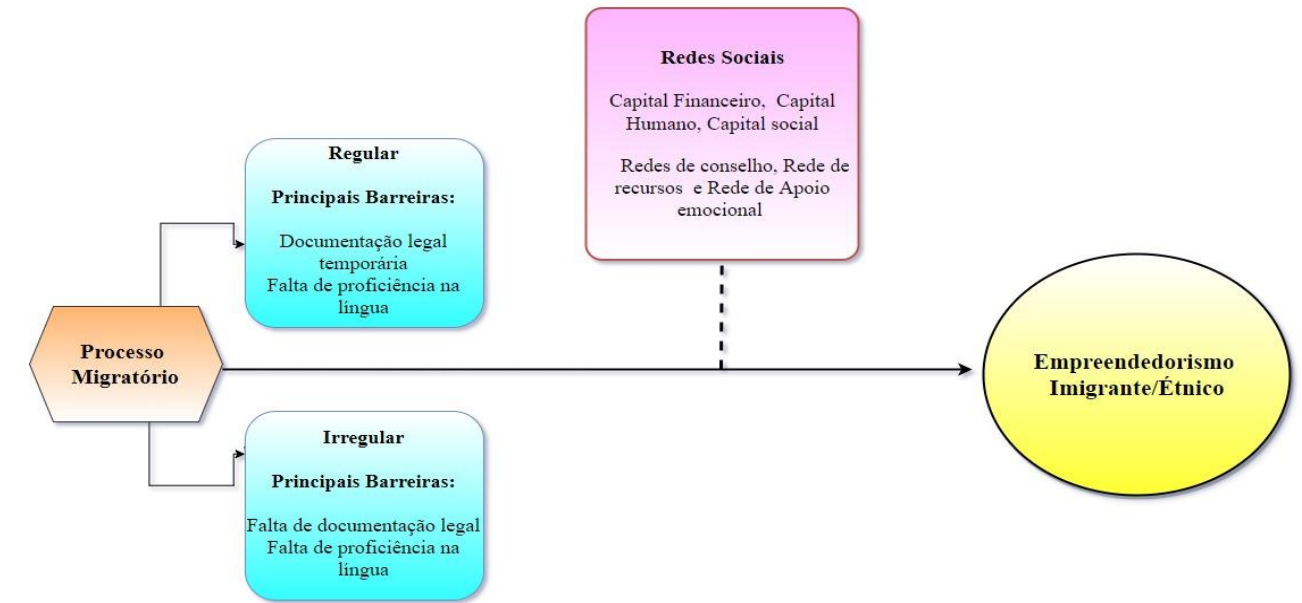

Fonte: elaborado pelos autores.

O modelo da Figura 1 busca representar os elementos essenciais que compõem o processo empreendedor imigrante. Dessa maneira, percebe-se que o início desse processo ocorre quando o imigrante decide se estabelecer em um novo país. De acordo com Zhou (2004), no processo migratório os contextos de saída são relevantes, dado que as condições em que o imigrante deixou seu país de origem, se voluntário ou involuntário, regular ou irregular, podem afetar o ambiente, as condições e as oportunidades no país de destino, independentemente do nível de capital humano, estrutural e cultural do indivíduo.

Após a realização do ato de migrar, o imigrante regular, bem como o irregular, enfrenta diversas barreiras para se estabelecer na nova sociedade de destino. Verificaram-se na literatura diversos autores, entre eles Zhou (2004), Portes (1981), Portes \& Sensenbrenner (1993), Light (1972) e Wilson \& Portes (1980), que encontraram resultados semelhantes em suas pesquisas empíricas. Eles apuraram que a falta de proficiência na língua, falta de documentação para a situação de regular, falta de escolaridade, entre outros, são barreiras que dificultam o imigrante se estabelecer no mercado formal de trabalho. Diante dessas dificuldades, muitos imigrantes tornam-se empreendedores, buscando sustento, geração de renda e inserção econômica e social no novo país onde se propôs a viver. Com a indisponibilidade de recursos financeiros oriundos de instituições formais de crédito dado ao seu status de irregular ou ausência de garantias para obtenção de empréstimos, parecem contar com o apoio de suas redes sociais para iniciar um negócio e promover o desenvolvimento de seu empreendimento (Granovetter, 1973, 1985; Halter, 2007; Portes, 1981; Portes \& Sensenbrenner, 1993; Wilson \& Portes, 1980; Zhou, 2004).

No modelo apresentado, em consonância com a literatura, consideram-se as redes sociais em uma linha tracejada como possível fonte de recursos de diversos tipos de capitais e diferentes formas de redes. De acordo com Aldrich \& Waldinger (1990), a falta de oportunidade de emprego leva imigrantes a buscarem oportunidades de negócios e condições de negócios no mercado étnico, objetivando sua sobrevivência. Kloosterman, Van Der Leun \& Rath (1999) reforçam o posicionamento de Granovetter $(1973,1983,1992,2005)$ de que a sobrevivência 
desses negócios é possível, haja vista que os empresários estão inseridos em redes sociais. E que os laços sociais formados a partir dos contatos com as díades fornecem aos empreendedores uma série de informações e recursos tais como financeiros, humano, social, entre outros. Autores, como Granovetter (1973, 1983, 1992, 2005), Sanders \& Nee (1996), Zhou (2004), Coleman (1988), Portes \& Sensenbrenner (1993), Portes \& Zhou (1992) e Arregle et al. (2015), reconhecem que a maioria dos empreendedores busca recursos financeiros por meio das redes sociais, sendo os laços fortes a principal fonte, especialmente familiares. Hite $(2003,2005)$ e Granovetter $(1973,1983,1992,2005)$ acreditam que a relação mantida entre os laços fortes e fracos são forças propulsoras de um processo de alavancagem social capaz de promover as relações econômicas de sucesso e as relações pessoais.

Outro aspecto importante registrado na literatura utilizado na elaboração do modelo teórico citado é abordado por Aldrich \& Waldinger (1990). Para eles, as estruturas de oportunidade oferecidas pelas redes sociais de coétnicos favorecem o empreendedorismo voltado para o mercado étnico. Os membros da rede social mobilizam acesso a recursos, facilitam a organização do negócio, auxiliam nas estratégias de gestão e ajudam na adaptação do novo ambiente. Estudos sobre etnias têm evidenciado que esse tipo de organização tem vantagens sobre os demais tipos. Essas situações, por conseguinte, proporcionam o que Portes \& Zhou (1992) e Zhou (2004) chamaram de solidariedade limitada, favorecendo o acesso a recursos e criando normas de relacionamentos e comportamentos entre os membros da rede que estejam passando por situações adversas no país de acolhimento. Entretanto, Zhou (2004) e Cruz et al. (2017) também identificam o perfil do empreendedor imigrante voltado para o mercado em geral. Esse empreendedor tem características um pouco distintas do empreendedor étnico. Sua principal diferença é o mercado de atuação e a relação mantida entre os coétnicos. Para os autores, os empreendedores que fazem a opção pela economia tradicional contam com o apoio de suas redes sociais para alavancagem de seu negócio, porém não são voltados para o enclave étnico e buscam se dissociar de seus coétnicos.

Ao estabelecer seu empreendimento no mercado, o imigrante parece ter grandes chances de expansão e de sucesso em sua atividade empreendedora. Vários estudiosos em suas pesquisas empíricas conseguiram verificar essas experiências, como, por exemplo, a Portes (1987) com refugiados cubanos em Miami. Nesse aspecto, percebe-se que o status do imigrante no país de acolhimento é de grande relevância, pois caso esteja irregular enfrentará fortes barreiras para a formalização e expansão de seus negócios. Enfim, a literatura revela que o processo empreendedor de imigrantes sofre diversas influências, perpassando desde seu contexto de saída até a escolha do tipo de negócio, bem como as possibilidades de expansão e formalização do mesmo. As etapas desse processo por vezes acabam propiciando um ciclo em que a chance de imigração de familiares para o país de acolhimento é incentivado e financiado por imigrantes já estabelecidos no novo país, fortalecendo e alimentando o empreendedorismo imigrante e étnico (Aldrich \& Waldinger, 1990; Arregle et al., 2015; Cruz et al., 2017; Portes \& Zhou 1992; Sanders \& Nee 1996; Zhou, 2004).

\section{Aspectos Metodológicos}

O presente trabalho é de natureza qualitativa, uma vez que a averiguação qualitativa trabalha com valores, crenças, hábitos, atitudes, representações, opiniões e permite o aprofundamento nos fatos e processos dos indivíduos e dos grupos. Assim, favorece a

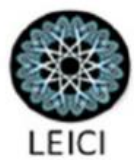


compreensão da complexidade envolvida nos fenômenos, sempre preservando a fidedignidade e a validade dos resultados obtidos (Paulilo, 1999). O método a ser utilizado será história de vida. De acordo com Miranda, Cappelle e Mafra (2014), esse método tem sido importante nas pesquisas realizadas no campo da Administração e nas pesquisas qualitativas, pois o mesmo possibilita compreender as particularidades dos objetos/sujeitos de pesquisa no âmbito individual ou coletivo. Lopes (2013) enfatiza que o método história de vida visa à compreensão do universo do qual os sujeitos fazem parte. A origem da utilização do método história de vida encontra-se nos trabalhos de Thomas \& Znaniecki (1927), que tiveram como objeto de estudo a organização, desorganização e reorganização de poloneses imigrantes nos Estados Unidos. Com base nos relatos coletados e das análises de documentos como cartas, os autores puderam compreender e interpretar a trajetória vivida pelos imigrantes, revelando a importância das mudanças sociais para aqueles imigrantes. Pesquisas empíricas nacionais pioneiras na utilização do método história de vida no campo da Administração, seja como método ou como técnica de coleta de dados (Cavedon \& Ferraz, 2005; Closs \& Antonello, 2011; Craide, 2011; Jaime, Godoy \& Antonello, 2007; Mageste \& Lopes, 2007), sugeriram a contribuição do método de história de vida nos avanços dos estudos organizacionais, entre os quais interculturalidade, processos e aprendizagem gerencial e administração mercadológica, e nos reflexos das representações sociais no desenvolvimento de estratégias. Miranda et al. (2014) afirmam que, mesmo de forma tímida, o método tem crescido no campo da Administração.

O método história de vida busca construir conhecimento de maneira a dar voz ao sujeito por meio de seu relato, ou seja, contando sua história. Por meio das entrevistas em profundidade e do diálogo entre o sujeito e o entrevistador, pode-se verificar o modo como o sujeito vive e como ele afeta e é afetado pela sociedade (Lopes, 2013). Nesse sentido, Barros e Lopes (2014) argumentam que o método história de vida é essencialmente abundante nos estudos relacionados a fenômenos ligados a movimentos e mudanças sociais, fenômenos de migração, mobilidade social, marginalização e exclusão, consequências de crises econômicas e sociais, bem como trajetórias de trabalho e mudanças profissionais. Enfim, considerando o objetivo deste trabalho, que busca analisar como as redes sociais no país de acolhimento atuam no apoio dos negócios dos empreendedores imigrantes sírios no Brasil, o método história de vida fornece a possibilidade de estabelecer conexões entre os pesquisados e seus âmbitos sociais e profissionais. Por meio das narrativas de cada imigrante é possível fazer o recorte de suas vivências e experiências na jornada do empreendedorismo. É por essas razões que se acredita ser a história de vida o método mais adequado para o entendimento do fenômeno da imigração no seu campo de vida real.

\subsection{Coleta de dados}

Esta pesquisa faz parte de um pesquisa ainda em desenvolvimento. Já foram ouvidos três imigrantes empreendedores e suas redes sociais no Brasil e estão sendo entrevistados imigrantes empreendedores brasileiros nos Estados Unidos, para efeito de comparação. Entretanto, para este trabalho será apresentado o relato de um empreendedor imigrante que está participando da pesquisa. Vale ressaltar que os resultados apresentados são preliminares, uma vez que a pesquisa encontra-se em andamento e entrevistas adicionais serão feitas com o imigrante em questão bem como com outros no Brasil e nos EUA. Os depoimentos revelam fatos e experiências vividas por ele na trajetória de vida até se tornar um empreendedor no

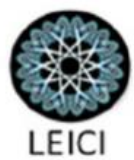


Brasil. Com a finalidade de complementar, enriquecer, triangular dados e dar validade à pesquisa, foram realizadas entrevistas com as redes de convívio do entrevistado, como familiares e amigos, de maneira a confrontar os relatos e acrescentar informações, fatos e documentos fornecidos por pessoas próximas. De acordo com Miranda et al. (2014), na adoção do método história de vida não há números fixos de entrevistas, pois a partir dos acontecimentos marcantes mencionados nos depoimentos e dos nomes citados poderá surgir a necessidade de investigação de novos elementos e a inclusão de novos entrevistados.

Foram realizadas entrevistas em profundidade, observação não participante e levantamento documental. De acordo com Paulilo (1999), as entrevistas realizadas no método história de vida são denominadas entrevistas prolongadas, na qual a interação entre o entrevistador e entrevistado se dá de forma contínua, podendo ser estabelecida como um encontro social, favorecendo a empatia, as percepções, sentimentos e emoções que propiciaram a narrativa do entrevistado. As entrevistas em profundidade permitem mapear e compreender o mundo da vida dos respondentes (Bauer \& Gaskell, 2017), sendo uma das mais importantes fontes de informações na pesquisa qualitativa, incluindo o estudo de caso individual como história de vida (Yin, 2005). Não foi elaborado roteiro para entrevistas, pois de acordo com Miranda et al. (2014), na operacionalização das entrevistas na história de vida não é adequada a estruturação de questões, pois se deve deixar o entrevistado à vontade para relatar sua história da maneira como lhe convier. O pesquisador deverá utilizar apenas a pergunta norteadora conteme a sua história e deixar que o entrevistado comece por onde achar mais adequado. Depois de estabelecido vínculo com o entrevistado, o pesquisador poderá direcionar questões ao respondente de acordo com o interesse de sua pesquisa.

Após a realização das entrevistas, foi realizada a transcrição das entrevistas, a elaboração da ficha do entrevistado e o diário de campo. A ficha do entrevistado contém informações básicas como nome completo, idade, país de origem, escolaridade e status de migração no país de destino. O diário de campo foi utilizado como auxilio nas anotações de como e em quais condições ocorreu a entrevista, bem como as percepções e sensações que permearam o depoimento. Posteriormente, foi realizada a leitura sistemática das transcrições das entrevistas a fim de levantar fatos e falas que revelem pontos de convergência e divergência em torno dos acontecimentos que contribuíram para que o imigrante se tornasse um empreendedor, bem como os recursos oferecidos pelas redes sociais nesse processo.

\section{Descrição do Caso: a História de Foad}

Foad, 36 anos, casado, natural da cidade de Aleppo/Síria, três filhos. Foad é um refugiado de guerra no Brasil. O entrevistado faz parte de uma família com pais e nove irmãos. Atualmente, em virtude da guerra, seus irmãos estão espalhados pelo Brasil, Alemanha, Síria, Jordânia e Turquia. Até a data deste relato seus pais estavam escondidos em um buraco em Aleppo, com água e comida restritas. Relata que quando morava na Síria trabalhava como chefe de cozinha do restaurante de uma grande empresa. Tinha boas condições de vida e financeira, possuía duas casas, carros e sua esposa não precisava trabalhar, cuidava da casa e das três crianças. O entrevistado conta que na cidade de Aleppo havia segurança e liberdade antes de a cidade ser atacada. As crianças podiam brincar na rua até tarde da noite e sua filha de 12 anos podia andar cheia de adornos de ouro em completa segurança. A guerra trouxe muita destruição

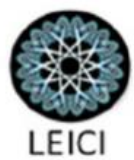


e o entrevistado e toda a sua família perderam tudo o que tinham e não havia como sobreviver, então foram tentar a vida na Jordânia.

Quando começou a guerra, a última cidade a ser atacada foi Aleppo, mas foi a pior cidade também [tosse, emoção]. A guerra então foi difícil, porque com guerra não tem trabalho, e se não trabalhar é difícil para gente viver, não tem alimento. Não pagava aluguel, mas tem outras coisas, temos que viver, tem alimento que precisa ser comprado, tem as crianças... Então como não havia trabalho, eu saí da Síria, e consegui ir para Jordânia e fiquei lá um ano e três meses.

Ao chegar à Jordânia, ainda enfrentou muitas barreiras. Foad diz que, na Jordânia, os sírios não têm autorização para trabalhar. Conta que passou fome com sua família e foi ajudado por uma igreja cristã local. Juntamente com essa igreja havia uma ONG brasileira chamada Missão em Apoio à Igreja Sofredora (MAIS), que ajudou Foad e sua família a vir para o Brasil. Ao chegar ao Brasil, foi para a cidade de Vitória, estado do Espírito Santo, antiga sede da ONG. Após curta estadia foi transferido para a cidade de Betim, por intermédio da igreja Batista da Lagoinha e de uma advogada chamada Renata. O entrevistado relata que a ONG o ajudou a solicitar o refúgio e a tirar os documentos legais aqui no Brasil. A igreja em Betim, Minas Gerais, ofereceu abrigo e custeou suas despesas por seis meses. Após esse período conseguiu trabalho na igreja como serviços gerais. Foad diz que, por não falar português, teve dificuldade em conseguir trabalho, e vendia quibe na igreja.

[...] a igreja arcou com todas as despesas por seis meses, depois de seis meses eles pagaram só o aluguel e parou de pagar água e luz. Eu sofri muito, foi muito sofrido porque teve a questão da língua, pois, para arrumar um emprego melhor precisava falar a língua e não tinha quem nos ensinasse, foi muito difícil. O trabalho que arrumei pagava um salário mínimo, ou seja, novecentos reais, mas, você recebe menos que isto porque tem os descontos, e isto aqui no Brasil não dá para fazer quase nada. E eu tenho três filhos e como vão viver com isto? Eu faço quibe para vender na igreja, ganha pouco.

Foad relata que esse período foi difícil e passou fome com sua família aqui no Brasil também. A advogada Renata que o ajudou a ir para a cidade de Betim ficou sabendo que ele estava passando por dificuldades e resolveu ajudar. A advogada fez contato com seus amigos por meio de redes sociais na internet e contou a situação de Foad. Muitas pessoas ajudaram, entre elas a família de Sr. Lorvandir, pessoa de grande influência em Betim, e atualmente muito importante na vida do entrevistado. Ana Paula, filha do Sr. Lorvandir, se disponibilizou a dar aulas de Português para os imigrantes e promoveu um jantar no qual Foad foi o cozinheiro. A intenção era apresentá-lo, bem como seus dotes culinários, para a alta sociedade de Betim. A partir desse jantar Foad começou a cozinhar em festas e eventos pela cidade. Na ocasião conheceu uma jornalista de um jornal de grande circulação na cidade, que se prontificou também a ajudá-lo. Escreveu sua história no jornal e criou uma página no facebook para divulgação de seu trabalho.

Aconteceu que a filha dele fez um jantar, eles já haviam ido até a nossa casa e gostaram muito da minha comida. Ela disse: eu vou fazer um jantar e convidar pessoas bem de vida para conhecerem sua comida. Daí comecei a fazer festas para eles. Ela fez uma festa e chamou pessoas bem ricas daqui. Na ocasião estava uma jornalista, o nome dela é Joelma e ela é daqui de Betim, tem um escritório aqui. Ela

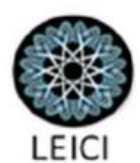


me disse: "olha, eu também vou te ajudar, vou fazer uma página para você, eu tenho muitos amigos no facebook, eu vou divulgar seu trabalho, também vou te ajudar".

Entre todas as manifestações de ajuda e apoio recebidas, Foad disse que não poderia deixar de relatar que o Sr. Lorvandir é muito importante para ele e sua família. Disse que a ajuda oferecida por ele não foi financeira, mas de cunho emocional, e o considera um pai brasileiro. Sr. Lorvandir comentou que, certo dia, ofereceu um jantar em sua casa para Foad e seu irmão recém-chegado da Síria, chamado Farahd. Nesse jantar Foad e sua esposa Yasmin pediram ao Sr. Lorvandir que ele e sua esposa fossem seus pais aqui no Brasil.

Nós fizemos um jantar para o Foad e para o Farahd, irmão dele que trabalha comigo lá na empresa. Durante a conversa, a Yasmim e o Foad pediram que a gente fossem pais deles aqui no Brasil. E aquilo foi uma emoção muito grande, e aceitamos ser pais deles aqui no Brasil. E esse negócio de ser pai passou a ser pai mesmo, assim, viver todos os problemas que tem aqui.

Logo após, uma sobrinha do Sr. Lorvandir sugeriu ao seu esposo, empresário na cidade, que abrisse um restaurante com Foad. O entrevistado relata que a princípio ficou receoso, pois não tinha recursos financeiros para montar um restaurante. Seu atual sócio, porém, disse que entraria com os recursos financeiros e ele entraria com o trabalho. Foad aceitou a proposta e hoje o restaurante está montado e em funcionamento. Sr. Lorvandir esclarece que ajudou Foad e sua família por perceber que seus próprios problemas são muito menores do que muitas pessoas que vivem neste mundo, como, por exemplo, pessoas em situações semelhantes à vivenciada por Foad. Os depoentes mencionaram um outro sírio que também recebeu apoio da Igreja e de sr. Lorvandir.

Tem outro sírio que também estava com a gente. Ele é solteiro e também estava na Igreja da Lagoinha. Acho que a Igreja cuidou dele por uns dois anos. Depois ele também estava sofrendo e não tinha trabalho direito, o pastor da Igreja disse: "tem um sírio aqui que está sofrendo e como ele não fala bem o português precisamos que você traduza para nós, para saber o que ele está sentindo e por que ele está sofrendo" Então eu fui até lá para ver e quando cheguei vi que ele estava sofrendo. Então falei com meu pai brasileiro e ele foi trabalhar com ele. Meu pai brasileiro abriu uma

\section{Análise do Caso} pequena empresa de marcenaria com ele para ele trabalhar e ele está trabalhando lá.

Verifica-se, nos relatos dos depoentes, que de acordo com o mencionado na literatura por Zhou (2004), Portes (1981), Portes \& Sensenbrenner (1993) e Wilson \& Portes (1980), bem como o apresentado pelo modelo teórico de análise dos dados, a falta de proficiência na língua e os contextos de saída do imigrante do país de origem afetam diretamente as oportunidades no país de destino, o que acabou levando Foad a se tornar um empreendedor com o objetivo de gerar recursos financeiros para sua subsistência e de sua família. Outro aspecto evidenciado pelas declarações é o importante papel desempenhado pelas díades formadas a partir das relações sociais. Eles são fontes de recursos financeiros, recursos sociais e até mesmo recursos emocionais, como mencionado por Granovetter (1973, 1985, 1992, 2005), Martes e Rodrigues (2004), Zhou (2004), Sanders \& Nee (1996), Portes \& Jensen (1989), Light \& Karageorgis (1994), Arregle et al. (2015), Wilson \& Portes (1980), Mariz e Bógus (2013), Peroni et al. (2016), Corrêa e Vale (2017), Vale e Guimarães (2010) e Vasconcelos et al. (2007). A partir dos depoimentos, inferiu-se que as redes formadas a partir dos laços fracos, como identificado

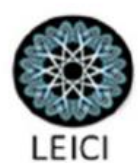


por Granovetter $(1973,1985,1992,2005)$, proporcionou acesso a recursos financeiros e recursos de apoio emocional, favorecendo e promovendo o empreendedorismo.

Então, eu preciso mencionar uma família, eles são como meu pai e minha mãe brasileiros, mas pai e mãe de verdade! Ele chama Lorvandir. Eles são pessoas muito boas. Elas para mim são melhores que mil igrejas. Tem que falar mesmo, ele nos deu carinho, acolhimento... ele não me ajudou com dinheiro, mas, ele ajudou com muita coisa. Agora eu falo assim com meu filho: “o Lorvandir chegou..." e ele já vai correndo para encontrá-lo lá fora. Porque ele dá muito amor e carinho, muito, muito.

[...] então a sobrinha do Lorvandir conhecia meu atual sócio. Ela falou para ele: "Por que você não tenta abrir uma restaurante, você vai ganhar bem com o Foad. Ele tem um posto de gasolina, o meu sócio é dono de um posto também. Então ele me chamou para conversamos e disse para abrirmos o restaurante...

Percebemos, no caso relatado, a relação imbricada entre atividade econômica e redes sociais - embeddedness, confirmando que as relações econômicas estão imersas nas relações sociais, e vice-versa; e estas estão incorporadas nas redes, cultura, política e religião. Constatamos que os laços de amizade e confiança entre os atores podem evoluir para laços econômicos, produzindo vantagens de diferentes ordens (Granovetter, 1985, 2005). Verificouse o relevante papel dos laços fracos, bem como o alcance das denominadas redes estendidas que podem gerar benefícios e acessos a oportunidades, como evidenciado no próximo relato:

Um dia o Foad me ligou e disse: Lorvandir, eu estou precisando de sua ajuda. Eu falei: o que foi, Foad? Tem um rapaz amigo nosso que veio da Síria, ele é marceneiro, arruma alguma coisa para ele, por favor. Eu falei: Foad, mais tarde eu vou passar aí na sua casa para conversar com ele, o nome dele é Toni. Fui conversar com o Toni, eu vi ele mexendo e disse: ô Toni, me dá uns dez a quinze dias para eu pensar em alguma coisa. Eu pensei, pensei, emprego não está tendo neste país, não tem emprego. Aí eu perguntei para ele quanto que custaria para montar uma marcenaria. Ele falou: Sr. Lorvandir para começar custa tanto. Aí eu perguntei: você quer montar alguma coisa? Vamos montar. Aí eu montei para ele e meu filho.

Entre as redes estendidas foi possível verificar o grande valor das redes sociais atuando como rede de conselho, rede de apoio emocional e rede de recursos na criação e manutenção de novos negócios, auxiliando o empreendedor na solução de problemas como fonte de recursos financeiros, desenvolvimento de competências empreendedoras e facilitando o crescimento e consolidação dos negócios (Arregle et al., 2015). Além das constatações em relação ao papel das redes, foi possível notar nos depoimentos o que Aldrich \& Waldinger (1990) afirmam: que diversas vezes imigrantes buscam oportunidades de negócios voltados para o mercado étnico, ligados à sua herança cultural, gerando o empreendedorismo étnico (Halter, 2007). Apurou-se também o empreendedorismo imigrante na atividade de marcenaria exercida por Toni, membro da rede social de Foad. De acordo com Zhou (2004) e Cruz et al. (2017), o empreendedorismo imigrante faz a opção por tipos de negócios não relacionados à sua etnia. Mesmo não pertencendo a um enclave étnico, foi possível verificar o depoente Foad exercendo o papel de minoria intermediária no apoio ao empreendedorismo imigrante de Toni, seu cóetnico. Para Zhou (2004), a categoria de minoria intermediária é composta por grupos étnicos que atuam como mediadores nas negociações entre as elites. Abstraiu-se essa atuação de Foad como ponte entre Toni e o Sr. Lorvandir. Detectou-se os empreendedorismos étnico e imigrante inseridos no contexto de economia de enclave e economia étnica, conforme sugerido por Wilson e Portes

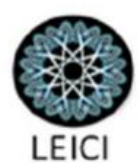


(1980) e Zhou (2004), em que é possível verificar tipos de negócios distintos funcionando como um guarda-chuva, incluindo negócios voltados para o mercado étnico bem como para o mercado atuante na economia em geral. Por fim, verificamos o aproveitamento do capital humano nas atividades exercidas por ambos os imigrantes, que empreenderam em atividades semelhantes as exercidas na Síria confirmando a teoria do capital humano mencionada por Sanders \& Nee, (1996) e Arregle et.al.,(2015).

\section{Considerações Finais}

Este trabalho buscou analisar como as redes sociais no país de acolhimento atuam no apoio dos negócios dos empreendedores imigrantes sírios no Brasil. Os relatos tiveram o objetivo de conhecer a história pessoal do entrevistado e entender como ocorreu o processo empreendedor e identificar os tipos de recursos disponibilizados pelas redes sociais na criação e manutenção de novos negócios. Por meio dessa rica história foi possível perceber a relevância do papel das redes sociais não apenas para facilitar e agilizar a adaptação do imigrante ao novo país, mas também como base de apoio para o estabelecimento de atividades empreendedoras. Os resultados confirmam as publicações, nas quais as redes sociais são fontes de vários tipos de recursos, entre eles capital financeiro, social e humano e como rede de apoio emocional, ajudando, assim, a fortalecer as ações empreendedoras de imigrantes (Zhou, 2004). A pesquisa também confirmou o que inúmeros autores já evidenciaram, ou seja, que as redes sociais são ferramentas valiosas para a criação e manutenção de novos negócios (Granovetter, 1973, 1983, 1985, 1992, 2005; Podolny \& Page, 1998; Portes \& Sensenbrenner 1993; Sanders \& Nee, 1996; Zhou, 2004, Vale \& Guimarães, 2010). Para esses autores, as atividades econômicas e sociais exercidas com o apoio de redes sociais geram vantagens competitivas e acesso a diversos tipos de recursos que são importantes para a alavancagem ou manutenção do empreendimento. Há de se ressaltar a limitação deste estudo por se tratar de história de vida única, entretanto, por meio da triangulação de dados, usando diferentes fontes de informações, foi possível estabelecer clara cadeia de evidência, confirmando os resultados obtidos com resultados semelhantes encontrados em outras pesquisas empíricas. Enfim, os resultados deste trabalho poderão ser utilizados para aprofundar pesquisas futuras que busquem compreender o papel das redes sociais no processo empreendedor, bem como compreender as abordagens do empreendedorismo imigrante e étnico.

\section{Referências}

Aldrich, H. E., \& Waldinger, R. (1990). Ethnicity and entrepreneurship. Annual Review of Sociology, 16(1), 111-135.

Arregle, J. L., Batjargal, B., Hitt, M. A., Webb, J. W., Miller, T., \& Tsui, A. S. (2015). Family ties in entrepreneurs' social networks and new venture growth. Entrepreneurship Theory and Practice, 39(2), 313-344.

Cavedon, N. R., \& Silva Ferraz, D. L. (2005). Representações sociais e estratégia em pequenos comércios. RAE-eletrônica, 4(1).

Barros, V. A., \& Lopes, F. T. (2014). Considerações sobre a pesquisa em história de vida. In: E. M. Souza (org.). Metodologias e analíticas qualitativas em pesquisa organizacional: uma abordagem teórica conceitual. Vitória: EDUFES. (296 p).

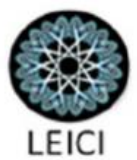


Bauer, M. W., \& Gaskell, G. (2017). Pesquisa qualitativa com texto, imagem e som: um manual prático. Petrópolis: Vozes.

Closs, L. Q., \& Antonello, C. S. (2011). O uso da história de vida para compreender processos de aprendizagem gerencial. Revista de Administração Mackenzie, 12(4), 44.

Coleman, J. S. (1988). Social capital in the creation of human capital. The American Journal of Sociology, 94.

Corrêa, V. S., \& Vale, G. M. V. (2017). A Dinâmica e a influência das redes sociais para o sucesso empreendedor. Revista Organizações em Contexto, 13(25), 1-19.

Craide, A. (2011). A adoção da história de vida em pesquisas sobre a interculturalidade: uma nova possibilidade de aplicação no campo da Administração. Anais do III Encontro de Ensino e Pesquisa em Administração e Contabilidade. EnEPQ, João Pessoa.

Cruz, E. P., Falcão, R. P. D. Q., \& Barreto, C. R. (2017). Estudo exploratório do empreendedorismo imigrante brasileiro em Pompano beach e Orlando-eua. Gestão \& Planejamento-G\&P, 18.

Granovetter, M. (1985). Economic action and social structure: The problem of embeddedness. American Journal of Sociology, 91(3), 481-510.

Granovetter, M. (1992). Problems of explanation in economic sociology. Networks and Organizations: Structure, Form, and Action, 25, 56.

Granovetter, M. (2005). The impact of social structure on economic outcomes. The Journal of Economic Perspectives, 19(1), 33-50.

Granovetter, M. (1973). The strength of weak ties. American Journal of Sociology, 78(6), 13601380.

Granovetter, M. (1983). The strength of weak ties: A network theory revisited. Sociological Theory, 201-233.

Halter, M. (2007). Cultura econômica do empreendimento étnico: caminhos da imigração ao empreendedorismo. Revista de Administração de Empresas, 47(1), 116-123.

Hite, J. M. (2005). Evolutionary processes and paths of relationally embedded network ties in emerging entrepreneurial firms. Entrepreneurship theory and practice, 29(1), 113-144.

Hite, J. M. (2003). Patterns of multidimensionality among embedded network ties: a typology of relational embeddedness in emerging entrepreneurial firms. Strategic organization,1(1), 9-49.

International Organization for Migration (2017). Measuring Global Migration Potential, 20102015. Retrieved from: https://gmdac.iom.int/gmdac-data-briefing-measuring-globalmigration-potential-2010-2015.

Jaime, P., Godoy, A. S., \& Antonello, C. S. (2007). História de vida: origens, debates contemporâneos e possibilidades no campo da administração. Anais do Encontro de Ensino e Pesquisa em Administração e Contabilidade, I. 2007, Recife. Anais. Recife EnEPQ, 2007.p.1-16.

Kloosterman, R., Van Der Leun, J., \& Rath, J. (1999). Mixed embeddedness:(in) formal economic activities and immigrant businesses in the Netherlands. International journal of urban and regional research, 23(2), 252-266.

Light, I. (1979). Disadvantaged minorities in self-employment. International Journal of Comparative Sociology, 20, 31. 
Light, I. (1972). Ethnic enterprise in America: Business and welfare among Chinese, Japanese, and Blacks. Univ of California Press.

Light, I., \& Karageorgis, S. (1994). The ethnic economy. The handbook of economic sociology, 647-71. Esses não estão no texto.

Lima, A. E. C., \& Castro, A. L. B. (2017). Brasileiros nos Estados Unidos: meio século (re)fazendo a América (1960-2010). Brasília: Fundação Alexandre Gusmão.

Lopes, F. T. (2013). Entre o prazer e sofrimento: histórias de vida, drogas e trabalho. Tese (Doutorado em Administração) - Universidade Federal de Minas Gerais, CEPEAD, Belo Horizonte (192 f.).

Mageste, G., \& Lopes, F. (2007). O uso da história de vida nos estudos organizacionais. Encontro de Ensino e Pesquisa em Administração e Contabilidade, 1, 116. Recife: EnEPQ.

Mariz, M. E. A., \& Bógus, L. M. M. (2013). Empreendedorismo feminino: imigrantes portuguesas em São Paulo. Brasiliana-Journal for Brazilian Studies, 2(2), 477-505.

Martes, A. C. B. (2016). Chegadas e partidas: migrações internacionais no Brasil recente. $G V$ executivo, 15(1), 30-33.

Martes, A. C. B., \& Rodriguez, C. L. (2004). Afiliação religiosa e empreendedorismo étnico: o caso dos brasileiros nos Estados Unidos. Revista de Administração Contemporânea, 8(3), 117-140.

Miranda, A. R. A., Cappelle, M. C. A., \& Mafra, F. L. N. (2014). Contribuições do método história de vida para estudos sobre identidade: o exemplo do estudo sobre professoras gerentes. Revista de Ciências da Administração, 59-74.

Oliveira, J. F. (2007). Empreendedorismo sem fronteira: desafios e conquistas dos imigrantes chineses no Brasil. Anais do XXXI Encontro da ANPAD - EnANPAD, Rio de Janeiro.

Paulilo, M. Â. S. (1999). A pesquisa qualitativa e a história de vida. Serviço Social em Revista, 2(2), 135-148.

Peroni, C., Riillo, C. A., \& Sarracino, F. (2016). Entrepreneurship and immigration: evidence from GEM Luxembourg. Small Business Economics, 46(4), 639-656.

Podolny, J. M., \& Page, K. L. (1998). Network forms of organization. Annual Review of Sociology, 24(1), 57-76.

Portes, A. (2003). Conclusion: Theoretical convergencies and empirical evidence in the study of immigrant transnationalism. International migration review, 37(3), 874-892.

Portes, A., Guarnizo, L. E., \& Haller, W. J. (2002). Transnational entrepreneurs: An alternative form of immigrant economic adaptation. American Sociological Review, 278-298.

Portes, A., \& Jensen, L. (1989). The enclave and the entrants: Patterns of ethnic enterprise in Miami before and after Mariel. American Sociological Review. Doi: 10.2307/2095716.

Portes, A. (1981). Modes of structural incorporation and present theories of labor immigration. In: Kritz,M.M., Keeley, C.B., \& Tomasi, S.M. (Ed.). Global trends in migration - theory and research on international population movements. Nova Iorque, Center for Migration Studies (pp. 279-297).

Portes, A., \& Rumbaut, R. G. (2006). Immigrant America: A portrait. Oakland: University of California Press.

Portes, A., \& Sensenbrenner, J. (1993). Embeddedness and immigration: Notes on the social determinants of economic action. American Journal of Sociology, 98(6), 1320-1350. 
Portes, A., \& Shafer, S. (2007). Revisiting the enclave hypothesis: Miami twenty-five years later. Research in the Sociology of Organizations, 25, 157-190. Doi: 10.1016/S0733558X(06)25005-5.

Portes A. (1987). The social origins of the Cuban enclave economy of Miami. Sociol. Perspect, 30:340-72.

Portes, A., \& Zhou, M. (1992). Gaining the upper hand: Economic mobility among immigrant and domestic minorities. Ethnic and Racial Studies, 15(4), 491-522.

Portes, A., \& Zhou, M. (2012). Transnationalism and development: Mexican and Chinese immigrant organizations in the United States. Population and Development Review, 38(2), 191-220.

Sanders, J. M., \& Nee, V. (1996). Immigrant self-employment: The family as social capital and the value of human capital. American Sociological Review, 61(2), 231-249. Doi: $10.2307 / 2096333$.

Sanders, J. M., \& Nee, V. (1987). Limits of ethnic solidarity in the enclave economy. American Sociological Review, 52(6), 745-773. Doi: 10.2307/2095833.

Thomas, W. I., \& Znaniecki, F. (1927). The wider community and the role of the press. The Polish Peasant in Europe and America, 2, 1367-397.

Vale, G. M. V., \& Guimarães, L. D. O. (2010). Redes sociais na criação e mortalidade de empresas. RAE-Revista de Administração de Empresas, 50(3).

Vasconcelos, G. M. R. D., Rezende, S. F. L., Guimarães, L. D. O., \& Fachin, R. C. (2007). Mobilizando relacionamentos e acessando recursos na criação e evolução de novos negócios. Organizações \& Sociedade, 14(41), 113-134.

Wilson, K. L., \& Portes, A. (1980). Immigrant enclaves: An analysis of the labor market experiences of Cubans in Miami. American Journal of Sociology, 86(2), 295-319.

Yin, R. K. (2005). Estudo de caso: planejamento e métodos. (2.ed.). Porto Alegre: Bookman.

Zhou, M. (2004). Revisiting ethnic entrepreneurship: convergencies, controversies, and conceptual advancements. International Migration Review, 38(3), 1040-1074. 


\begin{tabular}{|l|c|r|}
\hline XEGEPE & $\begin{array}{c}\text { Encontro de Estudos sobre Empreendedorismo } \\
\text { e Gestão de Pequenas Empresas }\end{array}$ & $\begin{array}{r}\text { São Paulo/SP } \\
04 \text { a } 06 \text { de julho } \\
\text { de } 2018\end{array}$ \\
\hline
\end{tabular}

